\title{
Oral Contributions
}

[MS34 - 04] X-Ray Diffraction In-Situ Study of Crystallization of Titania Thin Films.

R. Kužel ${ }^{1}$, A. Kadlecová ${ }^{1}$ L. Nichtová ${ }^{1}, Z$. Matěj $^{1}$, S. Kment ${ }^{2}$

${ }^{1}$ Faculty of Mathematics and Physics, Charles University in Prague, Ke Karlovu 5, 12116 Prague 2, Czech Republic, 'Institute of Physics, Academy of Sciences of the Czech Republic, Prague, Czech Republic

E-mail:kuzel@karlov.mff.cuni.cz

In previous studies on a series of amorphous magnetron deposited thin films with different thickness deposited on $\mathrm{Si}$ substrated it was found that the time evolution of crystallization expressed in terms of integrated intensity of anatase diffraction peaks could be always well described by simple modified Avrami (JMAK) equation and that the parameters of the equation as the crystallization onset and rate of crystallization were closely related to the film thickness. The crystallization of very thin films was rather slow. This seemed to be caused by tensile stresses created during the crystallization and inhibiting further crystallization [1]. The stresses were detected by diffraction peak shifts during annealing and measured at room temperature after annealing. The stresses were increasing with decreasing film thickness in the range of 50-800 $\mathrm{nm}$ [2]. In this work, in-situ high-temperature X-ray diffraction studies were performed on the set of $\mathrm{TiO}_{2}$ amorphous thin films prepared by the pulsed double hollow Ti cathode(s) plasma jet sputtering in order to verify the findings in particular on the stresses and/or find differences. By the reflectivity measurements it was found that these films were less dense and less homogeneous than the magnetron films and as a consequence the dependences of crystallization on the temperature and time were not so unique. However, most of basic features were confirmed. All these films crystallized at relatively low temperatures by a fast forming of relatively large crystallites (several tens of $\mathrm{nm}$ ), as follows from small XRD profile broadening, already from the beginning of crystallization. More compact films deposited by single cathode slowly crystallize at lower temperature starting at about $210{ }^{\circ} \mathrm{C}$ (magnetron films at $180{ }^{\circ} \mathrm{C}$ ) while sparse films deposited by double hollow cathode only at about $250{ }^{\circ} \mathrm{C}$. By more detailed analysis of peak shifts of several diffraction peaks at $2 \theta$ scan, it was confirmed that the tensile stresses were generated during the crystallization and the shifts were not related to changes of chemical composition (oxygen content). The tensile stresses were determined also at room temperature by the $\sin 2 \psi$ method for several diffracting planes and by total $2 \theta$ pattern fitting by using the software MSTRUCT [3]. The grain interaction seemed to be more close to the Reuss model. It was also confirmed that the stresses were higher for thinner films $(80-200 \mathrm{~nm})$. Differences were found in the texture and texture evolution. In magnetron films, at the beginning of crystallization the orientations of $\{101\}$ were supressed but at the end of process XRD showed nearly random grain orientations. In the plasma jet sputtered films, the pole figures indicated $\{001\}$ inclined texture more pronounced for thicker films and moreover unlike magnetron films the texture evolution during the crystallization was not significant.

[1] R. Kužel, L. Nichtová, Z. Matěj \& J. Musil, Thin Solid Films (2010) 519(5),1649-1654.

[2] Z. Matěj, R. Kužel and L. Nichtová, Metallurgical and Materials Transactions $\mathbf{A 4 2}$ (2011) 3323-3332.

[3] Z. Matěj, R. Kužel and L. Nichtová, Powder Diffraction ( 2010) 25, 125-131.

Keywords: titanium dioxide, crystallization, insitu measurements 